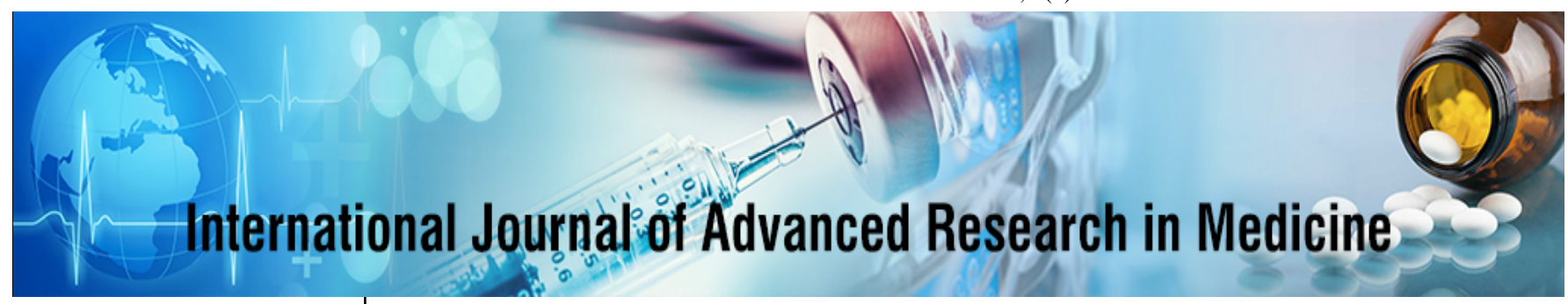

E-ISSN: 2706-9575

P-ISSN: 2706-9567

IJARM 2021; 3(2): 288-290

Received: 03-09-2021

Accepted: 29-09-2021

Dr. C Subrahmanyam Associate Professor,

Department of Pulmonology,

Kanachur Institute of Medical

Sciences, Mangalore,

Karnataka, India

\section{Microbiological profile and sensitivity pattern of endotracheal secretions in mechanically ventilated patients}

\author{
Dr. C Subrahmanyam
}

DOI: $\underline{\text { https://doi.org/10.22271/27069567.2021.v3.i2e.259 }}$

\begin{abstract}
Endotracheal intubation and mechanical ventilation are life-saving procedures done on emergency or elective basis to prevent or combat respiratory failure. Many clinical conditions warrant need for ventilatory support like, life threatening infections, sepsis and acute respiratory distress syndromes, neurological dysfunctions due to poisoning, drug toxicity, cerebrovascular accidents, trauma and others. The presence of an endotracheal tube in the airway, although critical for the management of the mechanically ventilated patient, also contributes to the development of ventilator associated pneumonia by disrupting normal protective mechanism which is associated with the intraluminal formation of biofilm by multidrug resistant organisms. Hence in our study endotracheal secretions were sent for bacteriological culture and sensitivity on the first day of intubation to identify the organisms that already existed at the time of intubation which would help in initiating and or modifying antibiotic therapy appropriately.
\end{abstract}

Keywords: Microbiology, profile, sensitivity, endotracheal, secretions, ventilator

\section{Introduction}

Endotracheal intubation and mechanical ventilation are life-saving procedures done on emergency or elective basis to prevent or combat respiratory failure ${ }^{[1]}$. Many clinical conditions warrant need for ventilatory support like, life threatening infections, sepsis and acute respiratory distress syndromes, neurological dysfunctions due to poisoning, drug toxicity, cerebrovascular accidents, trauma and others ${ }^{[2]}$. On one hand while mechanical ventilation helps to prevent deaths due to respiratory failure on the other hand it poses great threat, by leading to life threatening lung infections by itself due to various reasons that by passes host immune responses and infectious organisms getting access either by endogenous or exogenous route resulting in ventilator associated pneumonia (VAP) ${ }^{[3,4]}$. The presence of an endotracheal tube in the airway, although critical for the management of the mechanically ventilated patient, also contributes to the development of ventilator associated pneumonia by disrupting normal protective mechanism which is associated with the intraluminal formation of biofilm by multidrug resistant organisms ${ }^{[5]}$. These infections may result from ongoing growth of an agent that existed prior intubation which depend on various factors including pre-existing lung disease, prior colonizing organisms and oral commensals, as a part of systemic dissemination etc ${ }^{[6,7]}$. Hence in our study endotracheal secretions were sent for bacteriological culture and sensitivity on the first day of intubation to identify the organisms that already existed at the time of intubation which would help in initiating and or modifying antibiotic therapy appropriately and help in preventing the occurrence of ventilator associated pneumonia (VAP) or Hospital acquired pneumonia (HAP) and help bring about favorable outcome.

\section{Aims and Objectives}

To study the microbiological profile and sensitivity pattern of endotracheal secretions in mechanically ventilated patients.

Materials and Methods

This study was done in the Department of Pulmonology, Deccan College of Medical Sciences,
Dr. C Subrahmanyam Associate Professor,

Department of Pulmonology, Kanachur Institute of Medical Sciences, Mangalore,

Karnataka, India 


\section{Hyderabad.}

The study was done from September 2013 to August 2014.

Thirty patients were included in the study.

Endotracheal secretions were obtained on the day of intubation by sterile suctioning and the suction catheter tip was subjected for gram stain and culture. The positive culture samples were subjected to drug susceptibility testing.

\section{Inclusion Criteria}

Age more than 18 years.

\section{Exclusion criteria}

Patients on immunosupressor drugs or diagnosed to have immunosuppression.

\section{Results:}

Table 1: Mean age of the subjects

\begin{tabular}{|c|c|c|}
\hline Total & Mean age & Std deviation \\
\hline 30 & 44.82 years & 9.38 years \\
\hline
\end{tabular}

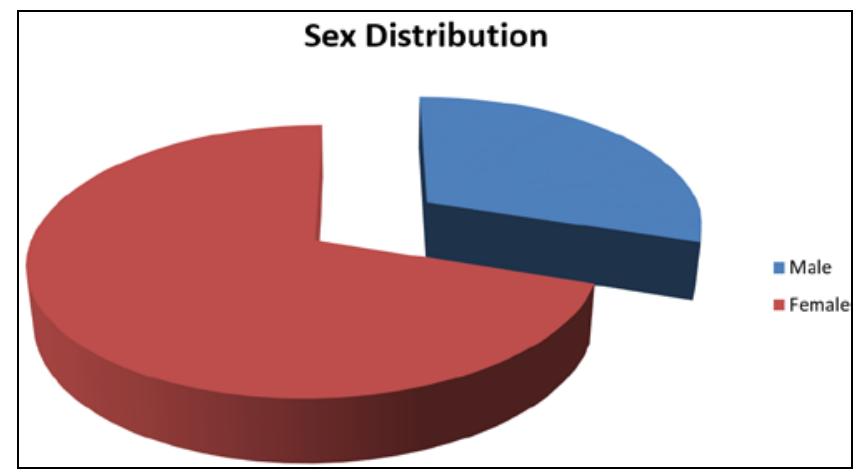

Graph 1: Sex Distribution

Table 2: Microbiology and sensitivity pattern

\begin{tabular}{|c|c|c|c|}
\hline Organism & Frequency & Sensitivity & $\begin{array}{c}\text { Resistance } \\
\text { (most common) }\end{array}$ \\
\hline Pseudomonas & 09 & $\begin{array}{c}\text { Amikacin, } \\
\text { Gentamycin, } \\
\text { Ciprofloxacin }\end{array}$ & Cefotaxime \\
\hline Elebsiella & 03 & $\begin{array}{c}\text { Amikacin, } \\
\text { Gentamycin, } \\
\text { Ciprofloxacin }\end{array}$ & Co-trimoxazole \\
\hline S. aureus & 02 & $\begin{array}{c}\text { Amikacin, } \\
\text { Gentamycin, } \\
\text { Imipenem }\end{array}$ & $\begin{array}{c}\text { Amox- } \\
\text { coClavulanate, } \\
\text { Co-trimoxazole }\end{array}$ \\
\hline $\begin{array}{c}\text { Mixed/ } \\
\text { Polymicrobial }\end{array}$ & 04 & - & $\begin{array}{c}\text { Amikacin, } \\
\text { Gentamycin }\end{array}$ \\
\hline No growth & 07 & - & - \\
\hline
\end{tabular}

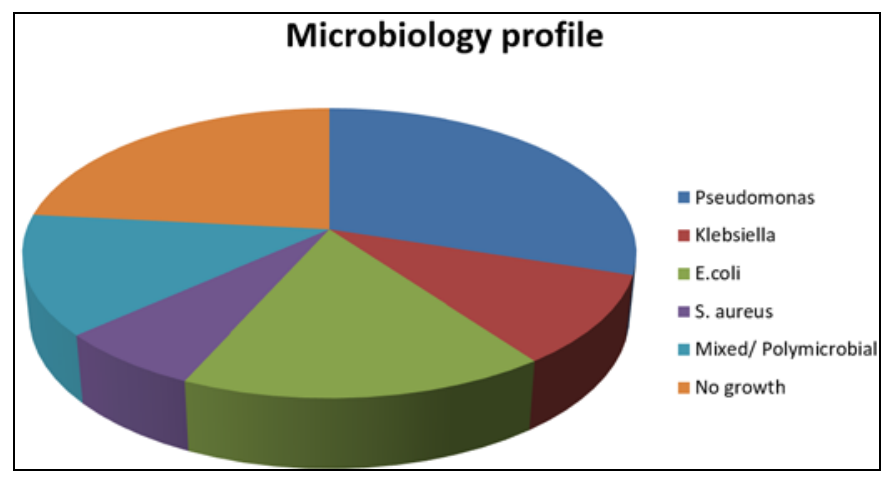

Graph 2: Microbiology Profile

\section{Discussion}

Gram negative organisms susceptible mostly to aminoglycoside \& carbapenem group of antibiotics form the predominant isolates in our critical care setup and the risk is higher in patients with pre-existing lung diseases. Initial appropriate empiric antibiotic therapy within few hours of admission to ICU helps in decreasing the mortality and duration of ICU stay. An updated local antibiogram for each hospital and ICU based on local bacteriological patterns and susceptibilities is essential to guide optimally dosed initial empiric therapy. With an empiric antibiotic regimen, deescalation is the key to reduce emergence of resistance. Culture of ET aspirate is easy, cost-effective procedure which helps in identifying the organism. Delays in initiation of antibiotic treatment may lead to poor outcomes. There is a risk of emergence of MDR pathogens with inadequate, inappropriate antibiotic treatment. Thus the microbiological profile \& sensitivity pattern of the local community helps in framing the appropriate institutional antibiotic policy for better outcomes.

\section{Conclusion}

An updated local antibiogram for each hospital and ICU based on local bacteriological patterns and susceptibilities is essential to guide optimally dosed initial empiric therapy.

\section{References}

1. Drakulovic MB, Bauer S, Torres A, JG, MJR, JA. Initial bacterial colonization in patients admitted to a respiratory intensive care unit: bacteriological pattern and risk factors. Respiration 2001;68:58-66. [Pub Med: 11223732].

2. Ortqvist A, Hammers-Berggren S, Kalin M. Respiratory tract colonization and incidence of secondary infection during hospital treatment of community-acquired pneumonia. Eur J Clin Microbiol Infect Dis 1990;9:725-731. [Pub Med: 2261917].

3. Durairaj L, Mohamad Z, Launspach JL et al. Patterns and density of early tracheal colonization in intensive care unit patients. J Crit Care 2009;24(1):114-121.

4. Corne P, Marchandin H, Jonquet O, Campos J, Bañuls AL. Molecular evidence that nasal carriage of Staphylococcus aureus plays a role in respiratory tract infections of critically ill patients. J Clin Microbiol 2005;43:3491-3493.

5. Garrouste-Orgeas M, Chevret S, Arlet G et al. Oropharyngeal or gastric colonization and nosocomial pneumonia in adult intensive care unit patients. A prospective study based on genomic DNA analysis. Am J Respir Crit Care Med 1997;156(5):1647-1655.

6. Koeman $\mathrm{M}$, van der Ven AJ, Hak E et al. Oral decontamination with chlorhexidine reduces the incidence of ventilator-associated pneumonia. Am J Respir Crit Care Med 2006;173:1348-55.

7. Patil T. The Study of the organisms colonising trachea in mechanically ventilated patients admitted in the intensive care unit (ICU). International Journal of Medical Science and Education, 2014, 1(1).

8. Summaiya M, Urmi J. Assessment of biofilm formation by the causative organisms of ventilator associated pneumonia at intensive care unit of a tertiary care hospital. National Journal of Medical Research 2012;2(1):15. 
9. Ferrer M, Ioanas M, Arancibia F, Marco MA, de la Bellacasa JP, Torres A. Microbial airway colonization is associated with noninvasive ventilation failure in exacerbation of chronic obstructive pulmonary disease. Crit Care Med 2005;33:2003-2009. [Pub Med: 16148472]. 